\title{
FURTHER TESTS OF THE EDTA TREATMENT OF BONES
}

\author{
Ingrid U Olsson \\ Department of Physics, Uppsala University, Box 530, SE-751 21 Uppsala, Sweden. Email: Ingrid_U.Olsson@Fysik.uu.se.
}

\begin{abstract}
A new suite of five dates on a whale rib from Varangerfjord was completed on different fractions obtained by EDTA treatment. The intention was to test the possible influence of contaminants, the criteria for complete reactions, and the reliability of the treatment in light of scattered values obtained earlier on samples from Varangerfjord. The yield on the treatment of the selected bone did, however, not allow any general conclusions regarding the influence of contaminants in nature. The results are interesting from an inter-sample comparison point of view. Included are observations, made during treatment, of $\mathrm{pH}$ and color changes as well as the appearance of the samples. These observations are provided as a reference for deciding when the treatment is complete.
\end{abstract}

\section{INTRODUCTION}

Berger et al. (1964) mentioned the possibility of using EDTA for bone treatment. They, however, suggested a dialysis bag, so the treatment seems less reliable than similar treatments in Groningen (Vogel and Waterbolk 1967:113; Grootes 1968) and in Uppsala. The EDTA ${ }^{1}$ method has been used in Uppsala since in 1964 and the first results were published 3 yr later (Olsson et al. 1967). The method was suggested in 1962 by Hendrik de Waard in Groningen, where he performed an EDTA treatment in the same year. The details of the method were given, and the reliability was examined in the laboratory (Olsson et al. 1974; El-Daoushy et al. 1978) using several bone samples, mostly from whales and seals from the Arctic region. The original method was further developed in Uppsala with recommendations that the material should be ground and that long extraction times be used to allow the liquids to penetrate into the inner parts. The extractions, each lasting normally two days or longer, should be repeated several times until no changes were observed for two or more extractions. This meant more than half a dozen extractions were needed. Special attention was also paid to the removal of EDTA from the sample because of the organic carbon. Studies of $\mathrm{pH}$, color, and appearance changes were used as criteria for the completion of the treatments. It was also found that the final step, introduced in Uppsala, was very important. At this step, the sample was divided into a "right" fraction $(\mathrm{R})$ and a "wrong" fraction (W), after the removal of any EDTA by adding dilute (0.1-N) $\mathrm{HCl}$, evaporation and a final dissolution in hot water to yield the "right" fraction, whereas the insoluble part was rejected as the "wrong" fraction. Many examples were given of samples yielding a wrong fraction with too young a date. At the same time, various $\mathrm{HCl}$ treatments were tested. The EDTA method proved to be the preferred one. It should, however, be remembered that the contamination may differ from sample to sample. Unsuccessful results can be used to discredit a fraction obtained when applying a certain method. A successful result does not allow the conclusion that a specific method always is good. When several people have treated the same sample by applying a certain method, possibly slightly differently or using various methods, and have obtained the same date within the limits of uncertainty, the probability increases that the method is reliable.

\section{EXPERIMENTAL TECHNIQUES}

\section{The Sample, its Treatment, Observations, and Activity Measurement}

\section{Earlier Dates from Varangerfjord}

The sample, a whale rib, was collected at Varangerfjord, Finnmark, northern Norway, and submitted by Joakim Donner. It was originally used for a comparison with a shell sample, Mytilus edulis, dated

${ }^{1}$ EDTA is the sodium salt of ethylenediamine tetraacetic acid. 
by the Helsinki Radiocarbon Laboratory. The shell sample was regarded as a reliable sample (Donner et al. 1977) in contrast to a Mya truncata sample. The $\delta^{13} \mathrm{C}$ value was given as $+1.7 \%$ and the original date, without any normalization for the $\delta^{13} \mathrm{C}$ value, as Hel-624: $4120 \pm 130 \mathrm{BP}$. The normalized age to be used is thus $4560 \pm 140$ BP. Five dates were presented by El-Daoushy et al. (1978). Two of them were determined on the same gas, after $\mathrm{HCl}$ treatment, but using two different proportional counters. Two of them were measured after the same EDTA treatment but one on the gas obtained at the degassing and the other at the real combustion. The ages as determined on gas from the $\mathrm{HCl}$ treatments, including usage of the iso-electric point, were significantly younger than those after the EDTA treatment. One $\delta^{13} \mathrm{C}$ value was significantly different from the other three values. The Helsinki age value was almost $2 \sigma$ younger than the mean of the two EDTA values from Uppsala. The significant spread implied that the whale rib might be suitable for further studies.

\section{Pretreatment and Summary of the EDTA Treatment}

The sample was partly covered by lichen. The outer layer was removed by scraping and sawing. The sample was washed twice in distilled water in an ultrasonic bath. It was dried and ground. As a result of this pretreatment the sample was reduced from 330 to $260 \mathrm{~g}$ before commencing the EDTA treatment. The main yield was three "right" fractions, each equivalent to about $2 \mathrm{~g}$ carbon. Each of these fractions was dated. The "wrong" fractions were much lighter in carbon but each was split into two halves of which one was further treated with successively stronger $\mathrm{HCl}$ to yield samples soluble in $1 \% \mathrm{HCl}, 1-\mathrm{N} \mathrm{HCl}$, and $4-\mathrm{N} \mathrm{HCl}$. The yield was so small that it seemed meaningless to date them in order to trace the contaminant. Two samples were, however, dated, although after dilution with inactive carbon dioxide to bring the gas pressure in the counter to a normal level. With a dilution factor higher than 10 the statistical uncertainty increased considerably. This was to some extent reduced by repeated measurements.

\section{Possible Explanation of an Error to be Examined}

Because of the younger ages obtained at the present investigation, further details regarding the treatments must be given to explain the differences.

Observations of the EDTA Treatment (in 1979)

The treatment with EDTA and the washings were performed in a beaker. The separation of the sample and liquid was possible by filtering, at the first treatment, and then by decanting and centrifuging in later steps. After four EDTA treatments, a quarter of the sample seemed gelatinous, after five treatments half of it, and after six, all of it was gelatinous. The liquid turned dark brown almost at once in the first treatment but was light brownish after the fourth, and light yellow-brownish after the sixth. No pH difference between the used EDTA and the prepared solution could be shown after three EDTA treatments. One-third of the sample was taken after three treatments for water washing and then half of the remaining sample after three further treatments. Thus there were three samples: 3 EDTA R, 6 EDTA R, and 9 EDTA R, where R stands for the "right fraction". The total time spent on the EDTA treatment was 26 days. The corresponding three "wrong fractions" were further treated as described above.

\section{Removal of EDTA}

The water wash, six washes for each of the right fractions, lasted in total 18, 14, and 17 days, respectively. The separation was performed by decanting and/or centrifuging. After two to four washes, the $\mathrm{pH}$ of the water seemed unaffected; it turned opalescent and was virtually colorless. 


\section{Notes on the Previous EDTA Treatment (in 1975)}

The treatment in 1975 was, however, made in a glass filter placed in a beaker. No notes on vacuum suction were found. The EDTA treatment lasted for 29 days and was performed in eight steps. After the sixth step, the $\mathrm{pH}$ was unaffected, and after the seventh time it was noted that the sample was soft. The sample was washed six times, in total for 27 days, the $\mathrm{pH}$ was affected in the first two washes, and for the last two washes the water appeared colorless. The explanation of the age difference is presently based on an argument of insufficient removal of the EDTA solution, since EDTA is synthesized from old carbon.

\section{Measurements}

The activity measurements were performed in 1979 and 1980 using carbon dioxide in the same counter (PR5) as used for four of the Varanger results in the 1978 publication. The sample values and the standard values for background and oxalic acid were re-evaluated in 1999. It was found that the statistics for each sample (background, oxalic acid, and the five samples) were very good.

Although the measurements were spread over more than a year, the electronics were adjusted during this period, so the measurements must be regarded as independent of each other. Indeed, three values for each of the background and oxalic acid had to be used. The $\delta^{13} \mathrm{C}$ values were determined in Stockholm by R Ryhage and his coworkers.

Table 1 All dating results after different treatments of a whale rib from Varangerfjord ${ }^{\mathrm{a}}$

\begin{tabular}{|c|c|c|c|c|}
\hline Lab nr & $\begin{array}{c}\delta^{13} \mathrm{C} \% o \\
(\mathrm{PDB})\end{array}$ & $\begin{array}{l}{ }^{14} \mathrm{C} \text { age } \\
(\mathrm{yr} \mathrm{BP})\end{array}$ & Treatment and fraction & Year treated, comments \\
\hline U-4128 & -16.7 & $4095 \pm 100$ & $\begin{array}{l}\text { Soluble in } \mathrm{HCl} \text {, iso-electric point, centrifuged, } \\
\text { dissolved in } \mathrm{HCl} \text {, centrifuged, dialyzed }\end{array}$ & 1975 \\
\hline $\begin{array}{l}U-4127 \\
U-2751\end{array}$ & -12.5 & $\begin{array}{l}4320 \pm 320 \\
4085 \pm 190\end{array}$ & $\begin{array}{l}\text { Insoluble in } \mathrm{HCl} \text {, dissolved by heating, iso- } \\
\text { electric point, centrifuged, dialyzed, dissolved } \\
\text { in } \mathrm{HCl} \text {, dialyzed }\end{array}$ & $\begin{array}{l}\text { 1975, same gas mea- } \\
\text { sured in } 2 \text { different } \\
\text { counters }\end{array}$ \\
\hline $\begin{array}{l}\text { U-4125 } \\
\text { U-4126 }\end{array}$ & $\begin{array}{l}-17.2 \\
-16.6\end{array}$ & $\begin{array}{l}5140 \pm 170 \\
4710 \pm 150\end{array}$ & EDTA (soluble in $\mathrm{H}_{2} \mathrm{O}$ - Right $\mathrm{f}$ ) & $\begin{array}{l}\text { 1975, degassing } \\
\text { 1975, real combustion }\end{array}$ \\
\hline U-4331 & -14.61 & $4530 \pm 120$ & EDTA, 3 times, (3 EDTA R) & 1979 \\
\hline U-4332 & -15.95 & $3960 \pm 220$ & EDTA, 6 times, (6 EDTA R) & 1979 \\
\hline U-4333 & -15.00 & $4310 \pm 90$ & EDTA, 9 times, (9 EDTA R) & 1979 \\
\hline U-4334 & -17.26 & $3760 \pm 350$ & $\begin{array}{l}\text { Insoluble in } 0.1-\mathrm{N} \mathrm{HCl} \text { after } 3 \text { EDTA, soluble } \\
\text { in } 1 \% \mathrm{HCl}\end{array}$ & $\begin{array}{l}\text { 1979, yield < one } \\
\text { tenth of } 3 \text { EDTA R }\end{array}$ \\
\hline $\mathrm{U}-4335$ & -17.10 & $4830 \begin{array}{l}+1080 \\
-940\end{array}$ & $\begin{array}{l}\text { Insoluble in } 1 \% \mathrm{HCl} \text { after } 3 \mathrm{EDTA} \text {, soluble in } \\
1-\mathrm{N} \mathrm{HCl}\end{array}$ & $\begin{array}{l}\text { 1979, yield }<<\text { one } \\
\text { tenth of } 3 \text { EDTA R }\end{array}$ \\
\hline
\end{tabular}

aResults are assumed to have the same age as a Mytilus edulis sample dated in Helsinki at $4560 \pm 140 \mathrm{BP}$, after normalization to $\delta^{13} \mathrm{C}=-25 \%$.

\section{RESULTS}

The results of the new investigation are given in Table 1 together with the previous results. The spread of the dates seems to be due to differences between the gaseous samples. The spread of the $\delta^{13} \mathrm{C}$ values also indicates a possible difference. The large $\sigma$-values for the two samples deriving from the "wrong fraction" are due to dilution. Similarly, part of the "right fraction" after six EDTA treatments was lost, so the statistical uncertainty is rather high. A small error in the background value will increase the uncertainty in the final normalized activity values for diluted samples. The 
difference between the oldest and youngest age values for the "right fractions", three EDTA R and six EDTA R, is slightly larger than $2 \sigma$. Despite this, the spread is not larger than can be expected to sometimes occur. The three new age values for "right fractions" are significantly younger than the mean age obtained in 1976 using the EDTA treatment and published in 1978. The two values obtained for fractions extracted from what normally is the "wrong fraction" (this time after three EDTA treatments) are not significantly different from the three "right fraction" dates. The $\mathrm{HCl}$ treatment in 1975 yielded fractions with not significantly different ages.

\section{DISCUSSION AND CONCLUSIONS}

The separation of the sample from the used EDTA solution or the water at the washings may have been much more efficient in 1979 than in 1975 because of the centrifuging. The importance of this step was already stressed in the papers from 1974 and 1978.

The conclusion is that EDTA treatment can yield reliable ages, when carefully applied. The sample should be ground. The EDTA extractions are not laborious but the treatment should be repeated several times and extended over long periods. Washing with water is very important and care should be taken to separate the sample from the liquid after each washing. Besides centrifuging, suction through a glass filter can be used. No severe contamination in nature could be detected at this investigation. The sample did not prove suitable for testing whether the EDTA method is reliable for any bone sample, but did prove suitable for testing the slow reaction in each step of the treatment.

The yield of the "wrong fractions" was too small to significantly affect the final results. Indeed these fractions were not evaporated down and then dissolved in water. The strong $\mathrm{HCl}$ dissolved material was burned after evaporation and should thus not be called "right fractions". For an extended investigation of the EDTA method, tests using a weaker $\mathrm{HCl}$ than $0.1-\mathrm{N}$ is suggested.

\section{ACKNOWLEDGMENTS}

The author is very thankful for the continuous support from the Swedish Natural Science Research Council during her employment in the Laboratory. I would like to thank Hans Nyhlén for being responsible for the present treatment together with me and the technicians, mainly one assisting in 1975 and another in 1979, and those assisting at the activity measurements. I will also address my thanks to the head of the Department allowing me to write this summary of old measurements.

\section{REFERENCES}

Berger R, Horney AG, Libby WF. 1964. Radiocarbon dating of bone and shell from their organic components. Science 144:999-1001.

Donner J, Eronen M, Jungner H. 1977. The dating of the Holocene relative sea-level changes in Finnmark, North Norway. Norsk Geografisk Tidsskrift 31:10328.

El-Daoushy MFAF, Olsson IU, Oro FH. 1978. The EDTA and $\mathrm{HCl}$ methods of pre-treating bones. Geologiska Föreningens i Stockholm Förhandlingar 100: 213-9.
Grootes PM. 1968. Bereiding van collagen uit botten voor dateringsdoeleiden. Thesis, Groningen. 69 p.

Olsson IU, El-Daoushy MFAF, Abd-El-Mageed AI, Klasson M. 1974. A comparison of different methods for pretreatment of bones. I. Geologiska Föreningens $i$ Stockholm Förhandlingar 96:171-81.

Olsson IU, Stenberg A, Göksu Y. 1967. Uppsala natural radiocarbon measurements VII. Radiocarbon 9:45470.

Vogel JC, Waterbolk HT. 1967. Groningen radiocarbon dates VII. Radiocarbon 9:107-55. 